\title{
QUE BRUMAS IMPEDEM A VISIBILIZAÇÃO DO CENTRO DE MATERIAL E ESTERILIZAÇÃO?
}

\author{
Rosani Ramos Machadoㄹ, Francine Lima Gelbcke²
}

\begin{abstract}
${ }^{1}$ Doutoranda em Enfermagem pelo Programa de Pós Graduação em Enfermagem (PEN) da Universidade Federal de Santa Catarina (UFSC). Docente da Universidade do Vale do Itajaí. Enfermeira da Secretaria de Estado da Saúde de Santa Catarina. Santa Catarina, Brasil. E-mail: rosaniramos@terra.com.br

${ }^{2}$ Doutora em Enfermagem. Professor Associado do Departamento de Enfermagem e do PEN/UFSC. Santa Catarina, Brasil. E-mail: fgelbcke@.ccs.ufsc.br
\end{abstract}

\begin{abstract}
RESUMO: Este artigo busca refletir sobre o processo e a organização do trabalho no Centro de Material e Esterilização na perspectiva do materialismo histórico e dialético e em contribuições teóricas sobre o trabalho no setor de serviços, considerando-se que mesmo com toda a necessidade deste serviço nas instituições de saúde, ainda é um trabalho invisível. Tal invisibilidade se deve, entre outros, a pouca ênfase dada pela academia à área; não ser um cuidado direto ao cliente; ter certa semelhança com o trabalho doméstico, sendo desvalorizado por estes fatores; geralmente está localizado em espaços escondidos na instituição; local onde se lida com dejetos, sujeiras, resíduos, secreções, odores; ausência do médico, profissional valorizado nas instituições de saúde. Alguns destes fatores são abordados ao longo desta reflexão, permitindo um novo olhar para o processo de trabalho em Centro de Material e Esterilização, buscando a sua visibilidade no contexto das instituições de saúde.
\end{abstract}

DESCRITORES: Enfermagem. Esterilização. Serviços de saúde.

\section{WHAT IS IT THAT IMPEDES THE VISIBILITY OF THE MATERIAL AND STERILIZATION CENTER?}

\begin{abstract}
This article seeks to reflect upon the process and organization of work in a Materials and Sterilization Center, based upon the perspective of historical and dialectic materialism, as well as theoretical contributions about work in the services sector, considering that even with all the necessities behind this service in health care institutions, it remains an invisible job. Such invisibility is due to the limited degree of importance given by academia; who do not consider it to be direct client care; it is valued less and comparable to domestic service. In so doing, it is devalued and generally placed in hidden locations within the health care institution, at times sharing space with waste, dirt, residues, secretions, odors, and the lack of physicians, who are the valued professionals within health care institutions. Some of these factors are outlined throughout this reflection, thus permitting a new perspective towards the Materials and Sterilization Center, seeking its visibility within the context of health care institutions.
\end{abstract}

DESCRIPTORS: Nursing. Sterilization. Health services.

\section{¿QUÉ BRUMAS IMPIDEN LA VISIBILIDAD DEL CENTRO DE MATERIAL Y ESTERILIZACIÓN?}

RESUMEN: En el presente artículo se reflexiona sobre el proceso y la organización del trabajo en el Centro de Material y Esterilización desde la perspectiva del materialismo histórico y dialéctico, así como en contribuciones teóricas sobre el trabajo en el sector de servicios, considerando que a pesar de la necesidad de ese servicio en las instituciones de salud, aún es un trabajo invisible. Tal invisibilidad se debe, entre otros aspectos, a la poca importancia dada por la academia al área; no es un servicio de atención directo con el cliente, y por lo mismo, es menos valorizado. Existe cierta semejanza con el trabajo domestico, el cual también es desvalorizado por ese mismo factor, ya que generalmente se encuentra localizado en lugares escondidos de la institución; es un lugar donde se trata con residuos, suciedad, secreciones, olores, y donde el médico, que es un profesional valorizado en la institución de salud, no se encuentra presente. Algunos de esos aspectos son considerados a lo largo de esta reflexión, ofreciendo una nueva mirada al proceso de trabajo en Centro de Material y Esterilización, buscando con ello, su visibilidad en el contexto de las instituciones de salud.

DESCRIPTORES: Enfermería. Esterilización. Servicios de salud. 


\section{CONSIDERAÇÕES INICIAIS}

O contexto social influencia as práticas de saúde e de enfermagem, desencadeando ações que interferem nos caminhos percorridos pela enfermagem, sendo, portanto, estes caminhos dinâmicos, mutáveis e sensíveis aos movimentos da sociedade. ${ }^{1}$

O trabalho em Enfermagem é uma prática social e interdependente de outras ações de saúde, constituindo-se também uma atividade, majoritariamente, institucional. Sendo parte do processo de trabalho em saúde, a Enfermagem, como qualquer outra profissão se apropria dos elementos deste como objeto, instrumentos, finalidade e produto, adaptando-os ao seu saber-fazer.

Mesmo dentro da Enfermagem existem especificidades em relação aos elementos do processo de trabalho, sendo o Centro de Material e Esterilização (CME) um dos setores em que estes elementos se diferenciam, sem, contudo esquecer que no âmbito global o objeto de trabalho dos profissionais de saúde é o ser humano.

O CME é a área das unidades hospitalares, dos Centros de Saúde ou de outros estabelecimentos de saúde, que executa a limpeza e o processamento de artigos e instrumentais hospitalares, bem como a que realiza o controle, o preparo, a esterilização, armazenamento e distribuição de materiais.

O Ministério da Saúde define CME como "[...] o conjunto de elementos destinados à recepção, expurgo, preparo, esterilização, guarda e distribuição dos materiais para as unidades dos estabelecimentos assistenciais à saúde" 2:15

O CME é uma unidade que costumava ser anexada ao Centro Cirúrgico (CC), mas com o desenvolvimento do conhecimento sobre infecções hospitalares e o aumento da variedade de materiais a serem processados, iniciou-se a sua separação do CC. Assim sendo, o CME torna-se uma unidade independente, que objetiva atender a todas as demais que necessitam de seu serviço, mesmo àquelas com uma demanda pequena de artigos médico-hospitalares, mas que possuem a mesma importância que o CC. ${ }^{4}$ Assim, os processos para limpeza, desinfecção e esterilização de materiais foram acompanhando a evolução das ações em saúde e, com o aumento da complexidade que envolvia os atos cirúrgicos, apareceu a necessidade de se criar mecanismos que evitassem a morte dos pacientes por infecção, dando-se início a uma reestruturação no processo de trabalho do
CME, além da criação de mecanismos que propiciassem o desenvolvimento de competências dos trabalhadores da área.

A enfermagem por ser, tradicionalmente, a categoria profissional responsável pela organização do ambiente e gerenciamento das unidades, assumiu as atividades desenvolvidas no $\mathrm{CME}$, seguindo "[...] a lógica da compartimentalização em que cada grupo profissional se organiza e presta uma assistência de saúde separada dos demais". .5:35

Historicamente, as atividades foram sendo desenvolvidas por atendentes de enfermagem ou outros trabalhadores sem qualificação específica para os procedimentos desenvolvidos no CME. Nestas unidades a coordenação freqüentemente é designada ao enfermeiro, porém ainda existem instituições que não mantém este profissional no CME, sendo comum o enfermeiro do CC ser responsável pelo gerenciamento deste setor. Nos serviços de saúde, o trabalho parcelar é mais facilmente identificado nas atividades de apoio e no exercício da Enfermagem, sendo que o profissional de nível superior é o que delega tarefas aos de nível técnico ou ocupacionais. ${ }^{5}$ Sendo assim, a qualificação sistemática dos recursos humanos que trabalham em CME é fundamental para o desenvolvimento de procedimentos de qualidade. Neste cenário, torna-se compreensível que somente profissionais qualificados e com capacitações permanentes, que tenham como eixo metodológico o processo de trabalho, podem provocar mudanças significativas na organização do trabalho em saúde e no CME, de uma forma particular, no controle de infecção hospitalar e na qualidade da assistência ao cliente, proporcionando uma visibilidade maior para as pessoas que atuam neste setor, uma vez que possui muitas atividades repetitivas.

O processo de trabalho se caracteriza por ser um conjunto de atividades, determinado por uma finalidade, em que o ser humano transforma um objeto em um produto, utilizando instrumentos de trabalho. No caso dos serviços de saúde, o objeto de trabalho é o ser humano-cliente que traz consigo as emoções, necessidades e vontades que gostaria que fossem atendidas pelo trabalhador da saúde.

No CME este processo é mais específico e, se configura, como objeto de seu trabalho os artigos a serem processados, tendo-os como produto final em "[...] condições seguras de uso, que irão subsidiar outros processos", 4:22 mantendo uma invisibilidade em relação à prestação do cuidado ao ser humano, mesmo para os trabalhadores, pois o produto se apresenta como a própria atividade destes. 
O produto do CME será consumido por outra pessoa, que vai estar em uma unidade da instituição ou até mesmo, outra instituição. Daí, talvez, a visibilidade em relação à prestação do cuidado ficar tão distante, não sendo percebida pelos trabalhadores.

A finalidade do CME é dar suporte às ações de saúde desenvolvidas pelos trabalhadores em estabelecimentos de saúde. Neste sentido, o CME presta "[...] cuidado ao cliente de maneira indireta, por instrumentalizar o cuidado direto prestado por outros setores ou serviços de saúde" ${ }^{\text {6:78 }}$

Como instrumentos de trabalho podem ser citados os materiais, ${ }^{7}$ tais como autoclaves, estufas, entre outros; metodológicos como organização por tarefa, e outros que indicam um modo de realizar o trabalho ${ }^{6}$ como a comunicação, a interação, a orientação, o conhecimento e o local de assistência que no CME tem uma organização específica de trabalho e que indica a finalidade do mesmo.

Por ser um serviço interno da organização, não produz um produto em si que seja vendável no mercado, mas que é necessário para que esta organização aconteça. Em princípio, o valor e o custo desse trabalho está embutido no preço final, já que são serviços diretamente referidos à produção (estoque, manutenção, reparos, limpeza). ${ }^{8}$ Portanto, a função reside na manutenção e no apoio à realização do processo de valorização do capital. Este processo, pode ser diferenciado ainda, em relação à esfera de serviços privados e públicos, pois estes últimos são avaliados pelo seu valor de uso e o critério de rentabilidade passa a ser substituído pelo critério de custo-benefício, além de critérios políticos. ${ }^{8}$

\section{A INVISIBILIDADE DO TRABALHO NO CENTRO DE MATERIAL E ESTERI- LIZAÇÃO}

Refletir sobre a invisibilidade do trabalho desenvolvido no CME está sendo um desafio, pois leva a tentar desvelar esta dimensão do processo de trabalho neste setor. Desta forma, é preciso identificar possíveis fatores que possam propiciar esta invisibilidade, que se pensa existir e que necessitará de um estudo investigativo mais aprofundado.

Existe uma invisibilidade dos microorganismos, os quais são invisíveis a olho nu, são organismos poderosos do mundo biológico e possuem potencial para causar injúrias ao ser humano, quando internado em ambiente hospitalar e, principalmente aos trabalhadores do CME. A não visualização dos riscos relacionados aos microorganismos permite uma exposição maior dos trabalhadores. No entanto, no cotidiano do trabalhador não é raro se negligenciar a importância dos microrganismos e os riscos que eles representam para a nossa saúde, pois "o contágio de fora não é capaz de ultrapassar nossos muros, nossa armadura, construídos ao longo de muitos anos de trabalho árduo, o que de certa forma nos torna 'imunes' a coisas tão insignificantes" 9:2

Entretanto, para superar esta situação é necessário aceitar, reconhecer e evitar o risco. Só que para isso acontecer deve-se perceber a situação criticamente.

Assim, começa-se a adentrar em conceitos que têm interface com outro aspecto, que é o da organização do trabalho no CME.

Para isso buscamos o conceito do que seja invisibilidade social. Antes, porém, encontramos o conceito de invisibilidade pública. Invisibilidade pública é conseqüência de uma divisão social do trabalho, que propicia uma percepção prejudicada do ser humano, enxergando-se a função e não a pessoa. Neste contexto, as relações trabalhistas interferem nas relações em que a alteridade inexiste, quando se deixa de pensá-los como sujeitos transformadores. ${ }^{10}$

Derivado do conceito de invisibilidade pública há uma perspectiva interessante para conceituar invisibilidade social, que vai além da invisibilidade por preconceito, abrangendo também aqueles que não vivem a margem da sociedade. ${ }^{11}$ A invisibilidade social pode ser descrita como "[...] relações sociais nas quais pessoas ou grupos sofrem uma ação invisibilizadora em determinadas situações. Esta não vem a mostrar que as pessoas tidas como invisibilizadas não sejam vistas. Elas são vistas através". 11:26

A visibilidade se revela com situações de enfrentamento, pelo mundo vivido e a invisibilidade pelo mundo não vivido. ${ }^{12} \mathrm{~A}$ invisibilidade se fundamenta no não revelado. A visibilidade se concretiza quando "a luta tem a ver não simplesmente com a mudança de comportamento individual, mas como uma mudança social de maior alcance, necessariamente destinada a enfrentar questões subjacentes de desigualdade e injustiça social". . $2: 101^{2}$

Assim, entendemos que com o CME ocorra uma ação invisibilizadora, pois são trabalhadores que são vistos e é um setor que existe, mas ambos não são efetivamente percebidos em sua existên- 
cia. Há, talvez, um acordo tácito de não mostrar, ou porque não, esconder este local de expurgo e de execução de tarefas de tão alta freqüência, isto é, "tarefas simples e rotineiras" realizadas cotidianamente. ${ }^{13: 77}$

Com estes conceitos buscamos possíveis fatores que propiciem a invisibilidade do CME no contexto do processo de trabalho das instituições ou organizações de saúde.

Um primeiro fator que surge é que o cuidado indireto/ meio é menos valorizado que o cuidado direto ao cliente, mesmo com o discurso de que este instrumentaliza a prestação do cuidado direto. Ratificando este fato, outro aspecto que deve ser levado em conta, ainda, é a pouca ênfase dada à área de CME na academia, pois a capacitação para atuar neste ocorre no âmbito da prática, levando a crer que o cuidado indireto tenha uma dimensão inferior ao cuidado direto, reforçando ainda mais a invisibilidade deste setor.

Salientamos, ainda, que mesmo sendo uma unidade com características especiais, em nossa formação pouca ênfase tem sido dada a esse conhecimento específico, sendo um local em que os acadêmicos ficam, em diversas situações, empacotando materiais, sem refletir sobre o fazer e sendo "mão-de-obra" barata. É relatado que "[...] a formação e o preparo para a realização dessas [...] práticas ocorrem antes no próprio âmbito do trabalho do que na academia. Poucos são os órgãos formadores em enfermagem que enfatizam um ensino específico em CM e em outros novos processos de trabalho" ${ }^{13: 19}$ Estes aspectos não favorecem a visibilidade deste setor como campo de atuação dos profissionais de enfermagem.

Surge, ainda, por nossa experiência, a noção de que mesmo dentro de uma mesma profissão, existem locais de trabalho que são mais ou menos valorizados que outros. Citamos como exemplos de locais valorizados: unidade de terapia intensiva, centro cirúrgico e unidades com muita tecnologia dura, como hemodinâmica, hemodiálise, entre outros. ${ }^{14} \mathrm{O} C \mathrm{CME}$ não é uma dessas unidades valorizadas, pelo contrário, para lá são alocados principalmente, trabalhadores que não se adaptaram à assistência direta ao cliente, por problemas de relacionamento interpessoal, assiduidade ou deficiência de conhecimento; trabalhadores em readaptação de função, que não suportavam mais permanecer de pé por longas horas, por exemplo, ou atendentes de enfermagem que só estão autorizados a executar as atividades elementares de enfermagem. Esta impressão é corroborada também por outros autores quando relatam que " [...] apesar da demanda dos enfermeiros pela melhoria de sua qualidade de operacionalização, o CM não era valorizado pelas direções dos hospitais, operando em locais inadequados e com recursos insuficientes ou antiquados. No mesmo caminho, o trabalho da enfermagem nesse local não era valorizado no conjunto da prática social da enfermagem, sendo permeado por um sentido desqualificatório e pejorativo e para lá encaminhados muitos profissionais da enfermagem que apresentavam 'problemas' de relacionamento nas unidades de assistência direta ao paciente" ${ }^{\prime 3: 14-5}$

Ao pensar na invisibilidade do trabalho do $\mathrm{CME}$, temos que nos reportar às questões de gênero, pois esta é uma área específica da Enfermagem onde também ocorre a predominância de mulheres e está implicado no contexto, historicamente marcado pela condição, ainda vigente, de menor reconhecimento do trabalho feminino.

No caso da enfermagem, ainda acontece que seu saber e experiência são pouco considerados ou desvalorizados pelos profissionais da área e, como conseqüência, pela sociedade. Dessa forma, são valorizados os saberes fundamentados na racionalidade instrumental e, no caso da saúde, centrado no saber médico, desconsiderando outros saberes "[...] mais relacionados ao viver compartilhado e que nos reportam às noções de limitação, dependência e coletividade, identificados aqui ao saber feminino, ao saber das enfermeiras". ${ }^{16: 19}$ Nesta visão os saberes tecnológicos, científicos e masculinos são relacionados à Medicina, enquanto o saber difuso, pouco científico e qualificado como um saber feminino cabe a enfermeira e a enfermagem de uma forma mais ampla. Assim, esse saber da enfermagem considerado "[...] polivalente, pouco palpável, com largas margens de indeterminação" 16:19 torna a enfermeira e a enfermagem como uma das profissões menos visíveis na área da saúde, sendo a enfermeira menos visível ainda devido ao número insignificante de profissionais no mercado de trabalho.

Pode-se considerar que "a enfermagem profissional incorpora o feminino, e este incorpora a invisibilidade histórica de um fazer 'menor, menos importante', por isso 'abaixo', simbólica e socialmente falando, de outros fazeres de igual nível acadêmico" ${ }^{16: 20}$ No mesmo sentido, pensamos que seja um local em que o trabalho se assemelha muito ao trabalho doméstico, na perspectiva de que sempre tem material para lavar, secar, arrumar, guardar, num círculo sem fim, se assemelhando muito a 
cozinha e lavanderia, pois são locais onde se faz limpeza e se acondicionam os produtos e utensílios para a sua realização. De uma forma geral, a "[...] limpeza de banheiros, alimentação, arrumação de camas e cuidados com a roupa são corretamente consideradas tarefas rotineiras; uma tarefa rotineira é essencialmente de alta freqüência e não adiável $^{\prime \prime},{ }^{17: 177}$ e como citado anteriormente são tarefas inferiores, consideradas de baixo valor. ${ }^{17}$ Por isso mesmo, escondemos muito bem nossas vassouras e panos de faxina, quando recebemos visitas em nossa casa. ${ }^{10}$ Portanto, utensílios e produtos de limpeza não são socialmente aceitos, assim o CME, por ser um local de limpeza e esterilização de material, considerado por muitos como um expurgo, também não o é. Esta atitude, esconder o que parecem instrumentos de atividades ditas de menor valor, passa a ser naturalmente aceito. Aceito, sem uso de força, aceito pelos outsiders que são estigmatizados como anormais pelos estabelecidos, que se reconhecem como elite. ${ }^{18} \hat{E}$ uma violência simbólica, pois são verdades construídas socialmente e este poder simbólico acaba transformando determinados hábitos e crenças em verdades legítimas. ${ }^{19}$

Daí, talvez, mais uma possibilidade para a invisibilidade deste setor. Este é percebido como importante somente quando não ofertado a quem necessita, porém não visualizado na rotina do cotidiano, por ser uma atividade meio.

Cabe igualmente lembrar, que a área da saúde faz parte do setor de serviços. Nesta configuração a estrutura social possui duas funções: de "[...] satisfação social das condições físicas de sobrevivência", $8: 15$ desempenhada pelas atividades econômico-produtivas e atividades que "[...] servem à manutenção ou modificação das formas de preenchimento da função inicialmente mencionada" ${ }^{8: 15}$ ou seja, manutenção ou modificação da forma das atividades anteriores. ${ }^{8}$ Neste contexto, o setor de serviços pertence à segunda função abrangendo as atividades que "[...] estão voltadas para a reprodução das estruturas formais, das formas de circulação e das condições culturais paramétricas, dentro das quais se realiza a reprodução material da sociedade" 8:15 Sob esta ótica, o CME é considerado um serviço interno à organização e tem uma função de acompanhamento do processo de produção com os serviços diretamente referidos à produção (estoque, manutenção, reparos, limpeza), sendo considerada uma atividade meio, por isso mesmo distante do consumidor final que não percebe esta fase no seu processo de cuidado a não ser quando acontece algo negativo, como uma infecção, por exemplo.

O CME é um dos setores das instituições de saúde em que a localização e arquitetura muito têm a dizer em relação à valorização dada a ele, tendo em vista os locais inadequados em que alguns ainda operam. Não raramente esta unidade fica localizada em locais inadequados ou anexos ao centro-cirúrgico.

Em relação à área física, sabe-se que a arquitetura influencia a dinâmica interna e as relações interpessoais. Neste conjunto, " [...] essa arquitetura pode ser considerada um elemento do currículo invisível ou silencioso, na medida em que institui em seu desenho um sistema de valores, tais como ordem, disciplina e vigilância [...]. O espaço [...] é dotado de significado, já que é fruto de uma construção social" ${ }^{20: 55}$

Criam-se espaços que facilitam a locomoção e interação entre as pessoas, sem muitas barreiras ou muitas divisórias ou, também, espaços construídos em que se colocam barreiras que dificultam o acesso, dividem e racionalizam os ambientes dificultando a qualidade das relações entre as pessoas..$^{20}$ Estas barreiras impedem o deslocamento dos trabalhadores. Neste caso, o deslocamento pode ser entendido como a possibilidade de transitar de um posto de trabalho a outro na organização. Isto possibilita a ocupação de espaços, representando uma forma de apropriação e poder. Estes deslocamentos criam pontos de contatos formais e informais, que possibilitam ao trabalhador, interagir com outros colegas fora do seu posto de trabalho. ${ }^{21}$ Devido às características da organização do trabalho no CME estes deslocamentos acontecem de forma restrita, diminuindo a possibilidade de interação de seus trabalhadores com um número maior de pessoas e setores na instituição. Este acesso restrito associado à localização pode potencializar a invisibilidade do $\mathrm{CME}$, pois a troca de saberes fortalece a prática e amplia o domínio do trabalhador sobre o ambiente do trabalho. No caso do CME, a restrição de seu domínio fragiliza a prática e mantém seu domínio circunscrito a sua área.

Ainda, o CME é um local onde se lida com as sujeiras, resíduos, secreções e odores. O ser humano vem progressivamente evitando a exposição dessa sua característica animal. Será que pode ser um dos motivos da falta de popularidade desse setor? Afinal, vivemos em "[...] um mundo moderno que tende para o inodoro, o desodorizado, o clean, cuja necessidade do controle de odores chega a todos os ambientes". 22:11 
Há ainda uma questão para se pensar: será que a ausência do médico neste processo influencia nesta invisibilidade? A participação do médico no processo de trabalho, principalmente, no hospital existe do início ao fim, pois ele que emite tanto a guia de internação hospitalar quanto a autorização da alta hospitalar. Entretanto, não participa do processo de trabalho deste setor, apesar de muitas das demandas serem provenientes de suas ações. Alguns autores referem que "[...] os estabelecidos, visando à manutenção de seu status, não se dispõem a exercer (determinadas) tarefas". ${ }^{11: 46}$ Para eles, quem quer que tivesse influência de status seria louco de envolver-se com uma responsabilidade de frequiência tão alta. Além das questões relativas a outras atividades, ela seria rejeitada como trabalho de muito baixo status. Partindo disso, pode-se pensar que existe "[...] uma verdade socialmente construída que o realizar determinadas tarefas pode rebaixar ou exaltar o indivíduo que as exerce". ${ }^{11-46}$

No caso em questão, os médicos na visão destes autores, seriam os estabelecidos, ou seja, aqueles que não se submetem às tarefas de alta freqüência $e$ de baixo valor social, mesmo que estas influenciem diretamente na qualidade de seu trabalho, no caso dos cirurgiões as atividades desenvolvidas no CME interferem de forma bastante efetiva.

Muitos são os motivos que levam a não percepção do valor do trabalho no CME. Um deles pode ser o fato de não se perceber todo o processo envolvido ao se apresentar o produto do trabalho, que são os artigos em condições seguras de uso. E qual é a utilidade social do material desinfetado/ estéril de forma segura?

Essa utilidade social parece não ser percebida pelos trabalhadores, gestores e usuários dos serviços de saúde, a não ser quando ocorrem infecções hospitalares. Essa invisibilidade acontece possivelmente devido ao processo de trabalho ocorrer por meio de ações fragmentadas "[...] em sua constituição social por exigência da divisão social e técnica do trabalho, no entanto, quando se concretiza no trabalho realizado, incorporado no organismo do indivíduo, se apresenta reunificada $\mathrm{e}$, neste momento, parece negar todo um processo anterior, justamente porque este não pode ser observado, nem direta, nem indiretamente no consumidor e, muito menos, num produto materialmente perceptível".7:74

A invisibilidade social do CME pode se justificar também porque o mesmo pode ser um lugar de economia para a instituição, pois os atendentes e auxiliares de enfermagem são os que geralmente recebem menos, no contexto hospitalar, além de possuírem menor qualificação, portanto é realizado um trabalho que é necessário, mas com utilização de recursos financeiros mínimos. Isto porque muitas instituições ainda mantêm a cultura de não investir na força de trabalho do CME em forma de capacitação e/ou formação ou lotação neste setor, de pessoal com formação. Sendo assim, os trabalhadores, por não possuírem qualificação adequada, provavelmente não conseguem atuar de modo que seu trabalho tenha um diferencial que possibilite a visualização por parte dos dirigentes e até mesmo, não conseguem perceber a distância que existe entre o trabalho realizado e o prescrito.

Visando também a redução de custos, os administradores podem não investir em infraestrutura, afetando o processo de trabalho deste setor. Desta forma, cria-se a possibilidade de existirem contradições entre o prescrito e o real, realizando-se ali, um trabalho muito distante do prescrito pela instituição.

Mas, e o que se pode fazer para propiciar a visibilidade do CME? Precisamos desenvolver ações que rompam com práticas que reproduzam a manutenção do status quo. Isso, necessariamente, implica na discussão da exposição a riscos biológicos, físicos, ergonômicos, entre outros. Implica ainda na compreensão do processo de trabalho no CME e sua interdependência com o processo de trabalho em saúde, em busca da percepção de seu valor social.

Seguindo um dos pressupostos da Política de Educação Permanente que sugere a intersecção entre o mundo da prática e o mundo de formação no cotidiano das instituições, acreditamos que a construção de estratégias para a visibilização do $\mathrm{CME}$ deva acontecer na prática das equipes. A academia pode ser um dos possíveis atores deste processo, fazendo uma reflexão sobre a abordagem deste espaço de trabalho nos currículos de enfermagem.

Entretanto, a instalação de um processo de mudança com a integração de novas práticas no cotidiano e o fortalecimento de práticas de trabalho que possam se aproximar do trabalho profissional, criativo e emancipador depende da participação dos gestores e dos trabalhadores em todo o processo de discussão.

\section{CONSIDERAÇÕES FINAIS}

Neste artigo refletimos sobre alguns aspectos que possam influenciar na invisibilização do CME no contexto hospitalar, tais como: o cuidado 
indireto/meio é menos valorizado que o cuidado direto ao cliente; a pouca ênfase dada pela academia à área; a noção de que mesmo dentro de uma mesma profissão, existem locais de trabalho que são mais ou menos valorizados que outros; é um local em que o trabalho se assemelha muito ao trabalho doméstico; a área da saúde faz parte do setor de serviços e as atividades desenvolvidas no CME, são atividades que visam dar sustentação as ações de saúde desenvolvidas nas unidades de saúde; a localização é escondida; é um setor onde se lida com as sujeiras, resíduos, secreções, odores; há ausência do médico e, ainda, é um local em que se encontram trabalhadores com menor grau de qualificação, apesar de já haver indicativos de mudança, podendo ser um lugar de economia para a instituição.

Pensar na invisibilidade do CME, nos faz refletir que ela está intimamente relacionada com a invisibilidade da Enfermagem como profissão. Contudo, sabe-se que a visibilidade de uma profissão acontece na construção diária de uma prática fundamentada em saberes tácitos e científicos, propiciando o surgimento de um reconhecimento social. Há que se ter, portanto, profissionais engajados, que lutem pelo reconhecimento social de sua profissão, pautados no conhecimento científico, no estabelecimento de competências que possibilitem as interações grupais. Por isso, a Enfermagem precisa cada vez mais desvelar e compreender seus nichos e, com isso fundamentar-se cientificamente buscando o fortalecimento e o reconhecimento da Enfermagem como disciplina.

Desta forma, os trabalhadores do CME necessitam engajar-se no processo de construção social da profissão, por meio de uma práxis reflexiva, superando o processo de alienação decorrente de um trabalho rotineiro. Há que se superar as dimensões ambivalentes encontradas no trabalho, tais como opressão e emancipação, alienação e criação, pois é com base no processo contínuo de reflexão, de conscientização, que o trabalhador necessita buscar constantemente compreender a sua vida no trabalho e a partir dele, tornando-o visível para si, para os outros e para a sociedade.

\section{REFERÊNCIAS}

1. Gelbcke F, Reibnitz KS. Empregabilidade: perda ou conquista da cidadania? In: Ciancirarullo TI, Cornetta VK. Saúde, desenvolvimento e globalização: um desafio para os gestores do terceiro milênio. São Paulo (SP): Ícone; 2002. p.199-234.

2. Brasil. Portaria Interministerial $\mathrm{N}^{\circ} 482$ de 16 de abril de 1999: dispõe sobre o regulamento técnico contendo disposições sobre o funcionamento e instalação de unidades de esterilização por óxido de etileno e suas misturas, bem como, estabelece as ações de inspeção sob responsabilidade do Ministério da Saúde e Ministério do Trabalho e Emprego. Diário Oficial da República Federativa do Brasil, 19 Abr 1999. Seção I. p. 15.

3. Moura MLPA. Centro de Material e Esterilização: planejamento e gestão. São Paulo (SP): SENAC; 2006.

4. Possari JF. Centro de Material e Esterilização: planejamento e gestão. $2^{\mathrm{a}}$ ed. São Paulo (SP): Iátria; 2005.

5. Pires D. A estrutura objetiva do trabalho em saúde. In: Leopardi MT. O processo de trabalho em saúde: organização e subjetividade. Florianópolis (SC): Papa-livros; 1999. p.25-49.

6. Taube SAM, Zagonel IPS, Méier MJ. Um Marco conceitual ao trabalho da enfermagem na central de material e esterilização. Cogitare Enferm [online]. 2005 Mai [acesso em 2007 Fev 13]; 2(10):76-83. Disponível em: http://calvados.c3sl.ufpr.br/ojs2/ index.php/cogitare

7. Leopardi MT. Instrumentos de trabalho na saúde: razão e subjetividade. In: Leopardi MT. O processo de trabalho em saúde: organização e subjetividade. Florianópolis (SC): Papa Livros; 1999. p.71-81

8. Offe C. Trabalho e Sociedade: Problemas estruturais e perspectivas para o futuro da "Sociedade do Trabalho". Rio de Janeiro (RJ): Tempo Brasiliense; 1991.

9. Koerich MS, Sousa FGM, Silva CRLD, Ferreira LAP, Carraro TE, Pires DEP. Biossegurança, risco e vulnerabilidade: reflexões para o processo de viver humano dos profissionais de saúde. OBJN [online]. 2006; 5(3): [acesso em 2006 Out 20]. Disponível em: http://www.uff.br/objnursing/index.php/ nursing/article/view/564/129

10. Costa FB. Homens Invisíveis: relatos de uma humilhação social Rio de Janeiro (RJ): Globo; 2004.

11. Rodrigues Junior GJ. (In) Visibilização Social: o jogo dramático de visibilidade e invisibilidade dos atores sociais [monografia]. Natal (RN): Universidade Federal do Rio Grande do Norte. Departamento de Centro de Ciências Humanas, Letras e Artes; 2007.

12. Parker R. A Aids no Brasil. Rio de Janeiro (RJ): Relume Dumará; 1994.

13. Bartolomei SRT. Processo de trabalho do enfermeiro no centro de material e seu lugar no processo de cuidar pela enfermagem [tese]. São Paulo (SP): Universidade de São Paulo. Escola de Enfermagem; 2003.

14. Merhy EE. Em busca do tempo perdido: a micropolítica do Trabalho Vivo em saúde. In: Merhy EE, Onocko R, organizadores. Agir em saúde: um desafio para o público. São Paulo (SP): Hucitec; 1997. 
15. Laus AM. A história da Central de Material: seu percurso em uma instituição de saúde de Ribeirão Preto [dissertação]. Ribeirão Preto (SP): Universidade de São Paulo. Escola de Enfermagem de Ribeirão Preto; 1998.

16. Pereira WR, Silva GB. A mulher, o trabalho e a enfermagem profissional - algumas reconsiderações sob a ótica do gênero. Texto Contexto Enferm. 1997 Jan-Mar; 6(1):18-32.

17. Douglas M, Isherwood B. O mundo dos bens: para uma antropologia do consumo. Rio de Janeiro (RJ): UFRJ; 2004.

18. Elias N, Scotson JL. Os estabelecidos e os outsiders. Rio de Janeiro (RJ): Jorge Zahar; 2000.

19. Bourdieu P. O Poder Simbólico. [S.1.]: Bertrand Brasil; 2000.
20. Nunes BO. O sentido do trabalho para merendeiras e serventes em situação de readaptação nas escolas públicas do Rio de Janeiro [dissertação]. Rio de Janeiro (RJ): FIOCRUZ/Escola Nacional de Saúde Pública; 2000.

21. Fischer FM, Gomes JR, Colacioppo S. Tópicos de saúde do trabalhador. São Paulo (SP): Hucitec; 1989.

22. Triska LNS. Prazer e bem estar no ambiente de trabalho: a importância do olfato na ergonomia [dissertação]. Florianópolis (SC): Universidade Federal de Santa Catarina. Programa de Pósgraduação em Engenharia de Produção; 2003.

23. Castanha ML. A (In)visibilidade da pratica de cuidar do ser enfermeiro [dissertação]. Curitiba (PR): Universidade Federal do Paraná. Programa de Pós-graduaçăo em Enfermagem; 2004. 